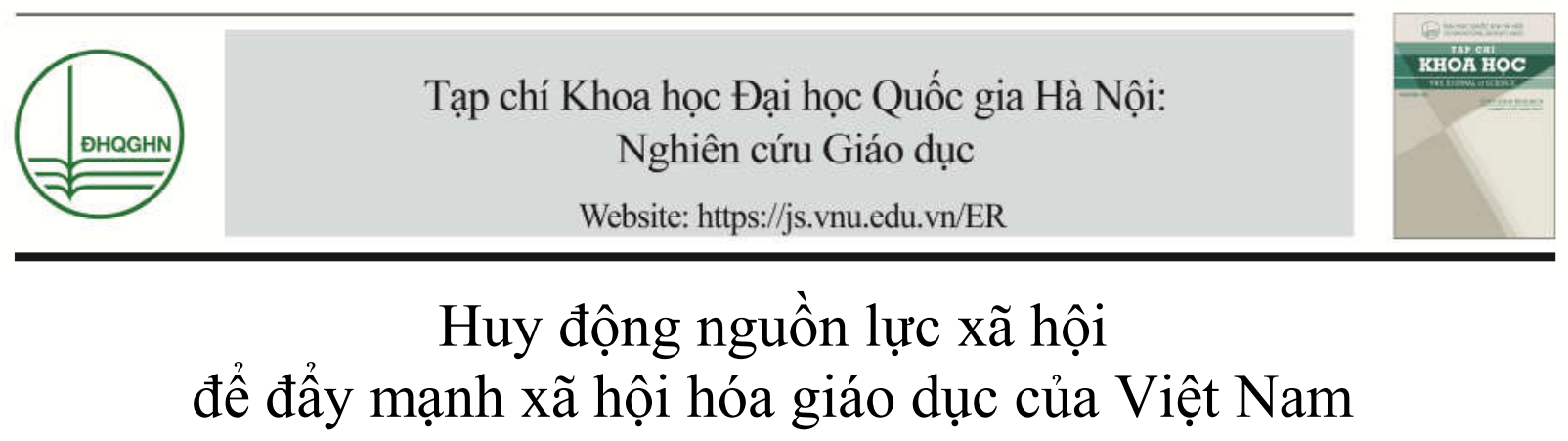

\author{
Nguyễn Thị Huyền Trang ${ }^{1, *}$, Trần Thị Hoài \\ ${ }^{I}$ Truờng Đại học Hòa Bình Hà Nội, Phố Bùi Xuân Phái, Tù Liêm, Hà Nội, Việt Nam \\ ${ }^{2}$ Viện Đảm bảo chất luợng giáo duc, Đại học Quốc gia Hà Nội, \\ 144 Xuân Thủy, Cầu Giấy, Hà Nội, Việt Nam \\ Nhận ngày 07 tháng 6 năm 2017 \\ Chỉnh sửa ngày 09 tháng 3 năm 2018; Chấp nhận đăng ngày 14 tháng 3 năm 2018
}

\begin{abstract}
Tóm tắt: Trên cơ sở phân tích công tác xã hội hóa giáo dục (XHHGD) của nước ta dựa trên các văn bản chính thức của Đảng và Nhà nước Việt Nam và thực tiễn XHHGD trong những năm qua bài báo đã trình bày những nguyên nhân chính của sự suy giảm hiệu quả của chính sách XHHGD, so sánh gữa XHHGD của nước ta với các đặc điểm cơ bản của một phong trào xã hội nói chung để rút ra kết luận về sự cần thiết phải huy động nguồn lực xã hội đề đẩy mạnh công tác XHHGD trong bối cảnh hiện nay.
\end{abstract}

Tù khóa: Xã hội hóa giáo dục, huy động nguồn lực xã hội, phong trào xã hội, nguồn lực sơ cấp.

\section{Mở đầu}

Xã hội hóa giáo dục là một chủ trương lớn của Đảng và Nhà nước. Do quy mô, tầm cỡ chiến lược mà quá trình chính sách xã hội hóa (XHH) nhìn chung là rất phong phú và đa dạng. Văn bản đầu tiên về chính sách XHH được phê duyệt và ban hành chính thức ngày 21/08/1997 là Nghị quyết (NQ) 90 của Chính phủ về phương hướng và chủ trương $\mathrm{XHH}$ các hoạt động giáo dục $(\mathrm{GD})$, y tế, văn hoá. Để cụ thể hoá NQ 90, ngày 19/8/1999 Chính phủ đã ban hành Nghị định $(\mathrm{NĐ}) 73$ nhằm khuyến khích, huy động các nguồn lực trong nhân dân, trong các tổ chức thuộc mọi thành phần kinh tế để

\footnotetext{
* Tác giả liên hệ. ĐT.: 84-982916169. Email: tranghbu6976@gmail.com https://doi.org/10.25073/2588-1159/vnuer.4083
}

phát triển các hoạt động XHH trong lĩnh vực GD, y tế, văn hoá, thể thao và thể chế hoá các chủ trương, chính sách đối với các hình thức ngoài công lập. Trên cơ sở những nghiên cứu của các học giả, các Hội nghị sơ kết, tổng kết việc triển khai thực hiện chính sách ở các cấp quản lí, kết quả điều tra dư luận xã hội trong nhóm chịu tác động, việc điều chỉnh chính sách đã được thực hiện thường xuyên từ cấp Chính phủ đển các Bộ, ngành, địa phương, từ quy mô toàn thể đến các vấn đề XHH khác nhau.

Ở cấp Chính phủ, điều chỉnh lớn nhất là việc ban hành NQ số $05 / 2005 / \mathrm{NQ}-\mathrm{CP}$ ngày $18 / 04 / 2005$ và $\mathrm{NĐ}$ số $69 / 2008 / \mathrm{NĐ}-\mathrm{CP}$ ngày $30 / 05 / 2008$. Gần đây nhất ngày $16 / 6 / 2014$ Chính phủ đã ban hành NĐ 59/2014/NĐ-CP sửa đổi, bổ sung một số điều của $\mathrm{NĐ} 69$ và sau đó là Thông tư số 156/2014/TT-BTC ngày 23/10/2014 của Bộ Tài chính. 
Tuy vậy, tầm quan trọng chiến lược cũng như mục tiêu của công tác XHH, gần đây đã bị thu hẹp so với chủ trương ban đầu. Nhiều vấn đề bức xúc trong GD chưa được giải quyết theo phương thức $\mathrm{XHH}$, nhiều đề xuất về chủ trương và giải pháp thực tiễn phát triển GD chưa được xã hội ủng hộ rộng rãi. Các trường đại học ngoài công lập như là một phương thức $\mathrm{XHH}$ đang lâm vào giai đoạn khủng hoảng khi mà đa số các trường không tuyển đủ chỉ tiêu để tồn tại. Cùng với việc thu phí tràn lan và việc dạy thêm học thêm diễn ra phổ biến từ lớp 1 ở các trường công lập ở khu vực đô thị, một hình ảnh lệch lạc về XHH GD ngày càng rõ nét. Mặt khác, việc mở rộng hệ thống các trường ngoài công lập và huy động vốn tư nhân để phát triển GD cũng chính là tư nhân hóa (privatization) GD là một trong ba nội dung cơ bản của thị trường hóa GD vốn lâu nay chưa có được sự đồng tình ủng hộ của xã hội. Niềm tin của xã hội vào chính sách XHH GD cũng như vai trò và hiệu quả của chính sách XHH GD vì thế ngày càng suy giảm, đòi hỏi phải có những chuyển biến mới, tích cực để góp phần xứng đáng vào việc phát triển sự nghiệp GD của đất nước.

Khi nói về vai trò và sức mạnh của nhân dân, trong bài viết "Dân vận" đăng trên tờ "Sự Thật" số 120 ngày 15/10/1949 Hồ Chí Minh đã khẳng định: "Cách mạng là sự nghiệp của quần chúng chứ không phải là sự nghiệp của cá nhân anh hùng". Chúng tôi cho rằng nguyên nhân của những tồn tại nêu trên chính là XHHGD mới chỉ dừng ở mức chủ trương chính sách của Đảng và Nhà nước mà chưa phát triển thành phong trào xã hội phát triển GD. Việc tiếp tục nghiên cứu những luận cứ khoa học và thực tiễ̂n cho việc phát triển XHHGD thành một phong trào xã hội sâu rộng trong cả nước vẫn là một vấn đề cấp thiết.

Chúng tôi giả thiết rằng để có chuyển biến mới, tích cực trong XHHGD việc trước tiên cần làm là đổi mới chủ trương và phương thức huy động nguồn lực, trong đó nguồn lực xã hội một thứ nguồn lực phi vật chất - cần được bổ sung cho việc lâu nay chỉ chú trọng huy động vật chất (trong đó có tài chính) và mở rộng hệ thống các cơ sở giáo dục ngoài công lập. Bài báo trình bày các nội dung sau: nguyên nhân chính của sự suy giảm hiệu quả chính sách XHHGD, sự khác biệt giữa XHHGD của nước ta hiện nay và một phong trào xã hội, những giải pháp đẩy mạnh việc XHHGD.

Phương pháp nghiên cứu bao gồm hồi cứu tư liệu và chuyên gia. Tư liệu trong nước được hồi cứu từ những năm 80 của thế kỉ 20 , một số tư liệu ngoài nước có liên quan đến thuyết huy động nguồn lực và phong trào xã hội trong thời gian gần đây. Các tác giả đã phỏng vấn 5 chuyên gia, những người đã từng tham gia soạn thảo các văn bản Nghị quyết, Nghị định của Chính phủ về XHHGD hoặc/và các chuyên gia nghiên cứu đề tài độc lập cấp Nhà nước về XHHGD của nước ta.

\section{Nguyên nhân chính của sự suy giảm hiệu quả chính sách xã hội hóa giáo dục}

Như đã trình bày, tầm quan trọng chiến lược cũng như mục tiêu của công tác XHHGD của nước ta, gần đây đã bị thu hẹp so với chủ trương ban đầu của Đảng và Nhà nước. Với việc hai NĐ kế tiếp của Chính phủ về chính sách khuyến khích XHH chỉ tập trung vào các cơ sở XHH, và cũng chỉ vào hoạt động tài chính của các cơ sở này, cùng với việc trên các phương tiện thông tin đại chúng tràn lan các tin tức về việc phụ huynh và học sinh, sinh viên hàng năm phải đóng góp bao nhiêu loại phí, lệ phí ở các trường công lập đã khiến cho XH hiểu sai lệch những nội dung cốt lõi của XHH. Để có thể xác định nguyên nhân chính của sự suy giảm hiệu quả chính sách XHHGD chúng tôi bắt đầu từ các loại nguồn lực được huy động trong xã hội cho GD, các cơ chế tiếp cận và những yếu tố có tác động thúc đẩy hoặc hạn chế việc huy động nguồn lực cho GD thực hiện các mục tiêu của XHGD.

Các học giả Việt Nam đã công bố những nghiên cứu về huy động nguồn lực xã hội nói chung và nguồn vật lực nói riêng. Đến nay, loại nguồn lực chủ yếu được huy động cho XHHGD ở Việt Nam là nguồn vật lực. Cũng như các phong trào xã hội khác trên thế giới, nguồn vật 
lực huy động cho XHHGD ở Việt Nam là nguồn lực có thể thay thế hầu hết và có lẽ có thể được chuyển đổi (fungibility) thành các nguồn lực khác khi nhu cầu bắt buộc. Trong mối tương quan với các nguồn lực khác, tiền có thể được chuyển đổi thành các nguồn lực khác thông qua việc mua thiết bị, thuê nhân viên, thành lập các tổ chức, tổ chức sự kiện, và trong việc sản xuất các nguồn lực văn hóa. Tuy nhiên, tính có thể chuyển đổi được của tiền có giới hạn rõ ràng, đặc biệt là khi muốn chuyển đổi sang các nguồn lực tỉnh thần như tính hợp pháp hoặc sự xác thực. Với một phong trào xã hội thì khái niệm truyền thống "có tiền mua tiên cũng được" không còn đúng đắn. Quá chú trọng vào huy động nguồn lực vật chất có tác động không thuận đến phong trào xã hội. Mặt khác, việc huy động nguồn vật lực ngoài ngân sách để lại nhiều hệ lụy trong quản trị, những thay đổi chính sách vĩ mô, đặc biệt là việc mở quá nhiều trường đại học công lập ở các ngành, các địa phương khiến cho nhiểu cơ sở tư nhân có nguy cơ giải thể, còn các hình thức XHH trong đơn vị công lập đã và đang tạo nên xung đột lợi ích, làm giảm tính minh bạch và công bằng trong cung cấp dịch vụ [5].

Loại nguồn lực thứ hai được quan tâm phát triển ở Việt Nam trong lĩnh vực GD là các tổ chúc phong trào GD (Education Movement Organization - EMO) như là: Hội Khuyến học (HKH) Việt Nam, Hội Cựu giáo chức Việt Nam, Hội Sinh viên Việt Nam, Hiệp hội các trường đại học và cao đẳng Việt Nam. Các trường phi lợi nhuận (not-for-profit) cũng thuộc loại nguồn lực này, tuy vậy, theo đúng nghĩa của một tổ chức phi lợi nhuận thì nước ta chưa có một trường nào. HKH là một EMO được phát triển rộng khắp cả về số tuyệt đối, quy mồ và độ bao phủ đến tận các làng xã. Tính đến năm 2015 , tổ chức HKH đã phủ kín 99,23\% xã, phường, thị trấn, 98,74\% xã, phường đã có Trung tâm học tập cộng đồng (HTCĐ). Quỹ Khuyến học của Hội riêng năm 2015, 63 tỉnh, thành đã huy động được gần 2000 tỉ (VNĐ) [6].

Nằm trong nhóm nguồn lực có giá trị sử dụng phụ thuộc bối cảnh, hoạt động và hiệu quả của các EMO này bị giới hạn trong các vấn đề cụ thể hoặc địa phương theo thời gian và địa điểm. Giá trị sử dụng của loại nguồn lực này phụ thuộc vào nhiều yếu tố văn hóa, xã hội và chính trị cũng như sự nỗ lực mà các EMO cần có. Theo phân loại của Colleman [1] thì các EMO của Việt Nam đều là các tổ chức xã hội có chủ ý được tạo ra đặc biệt cho các mục tiêu huy động nguồn lực xã hội phát triển GD. Ngoài mục tiêu chung này, các EMO đều có những mục tiêu cụ thể khác nhau.

Hệ thống các trường ngoài công lập (NCL) có đặc tính lợi nhuận nên khó có thể được xem là các $E M O$, tuy vậy lại là một phương thức huy động vật lực hiệu quả. Hệ thống NCL, theo số liệu 2013 [7], đã đảm nhận GD và đào tạo cho $1 / 2$ số trẻ mẫu giáo, $1 / 3$ số trẻ mầm non, 1/20 học sinh tiểu học, 1/200 học sinh trung học cơ sở, $1 / 10$ học sinh trung học phổ thông, gần $1 / 3$ học sinh trung cấp chuyên nghiệp, $1 / 5$ sinh viên cao đẳng và $1 / 7$ sinh viên đại học. Nếu tính rằng ngân sách nhà nước chi cho GD-ĐT là 104.775 tỷ VNĐ được đầu tư cho trường công lập ở các cấp bậc học (khoảng 20\% NSNN) thì khu vực NCL đã góp thêm vào đầu tư cho GD đào tạo ít nhất là $2 \%$ ngân sách. Một con số không nhỏ khi so sánh với đóng góp ngân sách của các ngành kinh tế khác [7].

Loại nguồn lực thứ ba là nhân lục được huy động cho các $\mathrm{EMO}$ có thể được đo bằng tỉ lệ dân cư có trình độ đại học. Nét đặc trưng của các EMO Việt Nam là những nhân vật sáng lập và lãnh đạo đều là các quan chức nhà nước cấp Bộ, Thứ trưởng GD đã nghỉ hưu. Báo cáo của TW Hội Khuyến học cũng chỉ ra đặc điểm cơ bản của việc huy động nhân lực của $\mathrm{HKH}$ là phụ thuộc vào địa lí và mật độ những người có bằng cử nhân trở lên trong khu vực. Việc thành lập các chi hội ở vùng sâu vùng xa, vùng có trình độ văn hóa trung bình thấp là khó khăn hơn so với ở vùng đồng bằng sông Hồng.

Sự hiếu học có thể được xem như một nét đẹp của bản sắc văn hóa Việt, một nguồn lực văn hóa - nguồn lưc thư tu, nhưng việc chuộng hư danh, hư học cũng là mặt trái của bản sắc này mà sự tồn tại của nó là một thực tế khách quan đòi hỏi các EMO hoặc các trường $\mathrm{NCL}$ phải xử lí trong quá trình huy động nguồn lực 
phát triển GD. Một ví dụ khác, trong khi ở miền Nam người dân không quan tâm nhiều đến việc học trường công hay tư miễn là đào tạo có chất lượng thì tư tưởng chính danh chính thống ở miền Bắc lại nặng nề tới mức các cơ quan tuyển dụng còn tuyên bố không tuyển nhân lực tốt nghiệp ở các trường tư hoặc các chương trình đào tạo tại chức. Có nhiều ví dụ để minh chứng tính hai mặt của nguồn lực văn hóa hoặc thúc đẩy hoặc cản trở quá trình XHHGD. Nguồn lực văn hóa, khi bước vào phạm vi công cộng, sẽ khó khăn hơn để kiểm soát bởi các cá nhân hoặc nhóm, ngay cả với những người tạo ra các nguồn lực này.

Nguồn lục tinh thần chưa được coi trọng khai thác trong phong trào XHHGD. Nền tảng đạo đức của các $\mathrm{EMO}$ như $\mathrm{HKH}$ và các tổ chức tình nguyện đều được xã hội công nhận nhưng các trường tư chưa tiếp cận được nguồn lực này. Trong khi lợi nhuận của một tổ chức không được nhà nước bao cấp là điều kiện tồn tại của họ thì Luật GD Việt nam "Cấm lợi dụng các hoạt động giáo dục vì mục đích vụ lợi”. Mặc cảm đạo đức vì lợi nhuận đối với các cơ sở tư thục đã hạn chế rất nhiều khả năng tiếp nhận nguồn lực tinh thần từ xã hội.

Cơ chế tiếp nhận nguồn lục trong XHHGD ở nước ta chủ yếu là tự sản sinh, tập hợp và bảo trợ. Cơ chế đồng hóa/chiếm dụng chưa tìm thấy được những bằng chứng có tính hệ thống về sự thực hành của nó. Các mối quan hẹ trao đổi được quan tâm phát triển. Các nhân vật phong trào XHHGD thường duy trì và bảo tồn nhiều mối quan hệ trao đồi. Sự tiết chế nguồn lực thể hiện đặc biệt trong tác động của Chính phủ đến các mục tiêu và chiến lược của các trường đại học tư khi đưa ra những chính sách ưu đãi đặc biệt cho các trường đăng ký hoạt động không vì lợi nhuận (xem ví dụ Luật GD đại học số 08/2012/QH13 do Quốc hội ban hành ngày 18/06/2012) và quy định về điều kiện để được hưởng chính sách ưu đãi như là một tổ chức XHH (xem Quyết định 693/QĐ-TTg ngày 06/05/2013 của Thủ tướng Chính phủ về việc sửa đổi bổ sung một số nội dung của Danh mục chi tiết các loại hình, tiêu chí quy mô, tiêu chuẩn của các cơ sở thực hiện xã hội hóa trong lĩnh vực giáo dục và đào tạo, dạy nghề, y tế, văn hóa, thể thao, môi trường ban hành kèm theo Quyết định số 1466/QĐ-TTg ngày 10/10/2008 của Thủ tướng Chính phủ).

Từ những phân tích trên đây có thể rút ra nhận xét rằng thấy rằng việc chưa huy động đầy đủ các loại nguồn lực có thể có trong xã hội với những phương thức hợp lí đối với mỗi loại nguồn lực là nguyên nhân chủ yếu dẫn đến sự suy giảm hiệu quả của chủ trương XHHGD.

\section{So sánh xã hội hóa giáo dục và phong trào xã hội}

Để có thể đề xuất được những giải pháp phát triển XHHGD thành một phong trào xã hội chúng tôi tiến hành một phép so sánh tổng thể giữa công tác XHHGD của nước ta với những đặc điểm cơ bản của một phong trào xã hội.

Phong trào xã hội chắc chắn liên quan đến hành động tập thể. Tuy nhiên, hành động tập thể này, mang hình thức của một phong trào chỉ khi nó được duy trì trong một thời gian dài. Hành động tập thể này không cần phải được tổ chức chính thức. Nó cũng có thể là một nỗ lực phi chính thức. Nhưng nó sẽ có thể tạo ra sự quan tâm và đánh thức rất nhiều người.

Một thành phần quan trọng của phong trào xã hội phân biệt nó với các thể loại chung của huy động tập thể là sự hiện diện của một hệ tư tưởng. Thí dụ, cuộc bãi khóa của sinh viên liên quan đến việc huy động tập thể và được định hướng hướng tới sự thay đổi. Nhưng trong trường hợp không có ý thức hệ, một cuộc bãi khóa học sinh trở thành một sự kiện bị cô lập và không phải là một phong trào. Ngược lại, nếu cuộc bãi khóa được thực hiện theo một hệ tư tưởng, nó có thể kéo dài trong thời gian dài hơn và mang hình thức của một phong trào.

Một phong trào xã hội thường được định hướng hướng tới sự thay đổi xã hội. Sự thay đổi này có thể là một phần hoặc toàn bộ. Mặc dù phong trào nhằm tạo ra sự thay đổi về các giá trị, chuẩn mực, ý thức hệ của hệ thống hiện tại, nhưng cũng có những nỗ lực khác để chống lại những thay đổi và duy trì hiện trạng. Các nỗ lực 
này thường là phòng thủ và phục hồi chứ không phải là sự đổi mới sáng tạo và khởi đầu. Đó thường là những nỗ lực có tổ chức của một trật tự đã được thiết lập để duy trì chính nó.

Như M.S.A. Rao [8] chỉ ra, mặc dù các nhà xã hội học gần như đồng ý với hai đặc điểm nêu trên hoặc phong trào xã hội; họ khác biệt rất nhiều về các tiêu chí khác - như sự hiện diện của một hệ tư tưởng, phương pháp tổ chức và bản chất của hậu quả.

Một phong trào xã hội có thể áp dụng kĩ thuật riêng của mình hoặc phương pháp để đạt được mục tiêu. Không có gì chắc chắn về nó. Nó có thể theo các biện pháp hoặc phương pháp hoà bình hoặc mâu thuẫn, bạo lực hoặc phi bạo lực, cưỡng ép hoặc thuyết phục, dân chủ hoặc phi dân chủ để đạt được mục đích của nó.
Điều tương tự cũng đúng với kết quả. Nó có thể thành công hoặc có thể thất bại; nó có thể trở thành một phần thành công hoặc ít nhất nó có thể tạo ra sự "đánh thức" chung trong công chúng về một vấn đề. Kết quả của một phong trào có một sự gắn bó chặt chẽ - hệ tư tưởng và khuôn khổ tổ chức.

Như Paul Wilkinson [9] đã chỉ ra rằng một phong trào xã hội đòi hỏi tối thiểu là khuôn khổ tổ chức để đạt được thành công hoặc ít nhất để duy trì tiến độ của phong trào. Để làm cho sự phân biệt rõ ràng giữa các nhà lãnh đạo và những người đi theo, để làm rõ mục đích của phong trào, thuyết phục mọi người tham gia hoặc ủng hộ nó, áp dụng các kĩ thuật khác nhau để đạt được các mục tiêu - một phong trào xã hội phải có một khuôn khổ tổ chức nào đó.

Bảng 1 . Trình bày những kết quả so sánh giữa XHHGD của nước ta và một phong trào xã hội

\begin{tabular}{|c|c|c|}
\hline Nội dung & XHHGD & Phong trào xã hội \\
\hline Mục đích & $\begin{array}{l}\text { Khuyến khích, huy động các nguồn lực } \\
\text { trong nhân dân, trong các tổ chức thuộc } \\
\text { mọi thành phần kinh tế để phát triển các } \\
\text { hoạt động XHH trong lĩnh vực GD }\end{array}$ & $\begin{array}{l}\text { Tạo ra sự thay đối về các giá trị, chuấn mực, ý thức } \\
\text { hệ của hệ thống hiện tại, nhưng cũng có những nỗ } \\
\text { lực khác để chống lại những thay đổi và duy trì hiện } \\
\text { trạng }\end{array}$ \\
\hline Đặc điểm & $\begin{array}{l}\text { Là một hành động của các gia đình và } \\
\text { toàn xã hội và được duy trì lâu dài }\end{array}$ & $\begin{array}{l}\text { Là một hành động tập thể được duy trì trong một } \\
\text { thời gian dài }\end{array}$ \\
\hline $\begin{array}{l}\text { Phương } \\
\text { thức }\end{array}$ & Chính thức & Chính thức hoặc phi chính thức \\
\hline $\begin{array}{l}\text { Hệ tư } \\
\text { tưởng }\end{array}$ & $\begin{array}{l}\text { Chủ trương chính sách của Đảng và Nhà } \\
\text { nước }\end{array}$ & Sự hiện diện của một hệ tư tưởng \\
\hline $\begin{array}{l}\text { Phương } \\
\text { pháp }\end{array}$ & $\begin{array}{l}\text { Theo các phương pháp hòa bình và dân } \\
\text { chủ }\end{array}$ & $\begin{array}{l}\text { Theo các biện pháp hoặc phương pháp hoà bình } \\
\text { hoặc mâu thuẫn, bạo lực hoặc phi bạo lực, cưỡng ép } \\
\text { hoặc thuyết phục, dân chủ hoặc phi dân chủ đề đạt } \\
\text { được mục đích của nó. }\end{array}$ \\
\hline Kết quả & $\begin{array}{l}\text { Luôn thành công ở những mức độ khác } \\
\text { nhau }\end{array}$ & $\begin{array}{l}\text { Có thể thành công hoặc có thể thất bại; nó có thể } \\
\text { thành công một phần hoặc ít nhất có thề tạo ra sự } \\
\text { "đánh thức" chung trong công chúng về một vấn đề }\end{array}$ \\
\hline Tổ chức & Được tổ chức thực hiện bởi Nhà nước & $\begin{array}{l}\text { Đòi hỏi tối thiểu một khuôn khổ tổ chức để đạt được } \\
\text { thành công hoặc ít nhất để duy trì tiến độ của phong } \\
\text { trào. }\end{array}$ \\
\hline Công cụ & Huy động nguồn lực & Huy động nguồn lực \\
\hline \multirow[t]{5}{*}{ Nguồn lực } & Nhân lực & Nhân lực \\
\hline & Vật lực (bao gồm cả tài chính) & Vật lực \\
\hline & Nguồn lực tổ chức (EMO, NCL) & Nguồn lực tổ chức (EMO, NCL) \\
\hline & & Văn hóa \\
\hline & & Tinh thần \\
\hline
\end{tabular}


Từ những so sánh nêu trên có thể rút ra kết luận rằng xét về đặc điểm, kết quả, phương thức, phương pháp và tổ chức thì XHHGD của nước ta có thể xem là một phong trào xã hội nói chung. Tuy vậy, về mục đích, hệ tư tưởng và nguồn lực thì có sự khác biệt.

Sự khác biệt về mục đích cũng là lẽ thường bởi vì theo định nghĩa thì mỗi phong trào xã hội đều có những mục đích riêng của nó.

Về hệ tư tưởng thì cho đến nay có thể nói XHHGD của nước ta vẫn được hiểu là một chủ trương chính sách của Đảng và Nhà nước, trong đó Nhà nước đang chủ trì tổ chức thực hiện. Nó chưa thực sự là một nhận thức mới mang tính tự giác của đông đảo các tầng lớp nhân dân. Bằng chứng là trên các phương tiện thông tin đại chúng có nhiều ý kiến trái chiều về việc huy động vật lực cho phát triển giáo dục xuất phát từ việc thu phí tràn lan ở các trường trung học, tiểu học và học phí ngày càng tăng ở các trường đại học công lập. Các trường NCL được hiểu như là một cách huy động nguồn lực nhưng bản chất vì lợi nhuận của nó đã khiến cho dự luận xã hội chưa có được những sự ủng hộ về tinh thần cần thiết. Vì thế, bên cạnh những thành tựu mà XHHGD mang lại những vấn đề bức xúc nảy sinh trong xã hội cũng cần phải quan tâm giải quyết.

Chúng tôi quan tâm đặc biệt đến sự khác biệt về nguồn lực. XHHGD của nước ta, căn cứ vào các văn bản chính thức của Đảng và Nhà nước cũng như thực tiễn triển khai cho thấy mới chỉ chú trọng huy động nguồn nhân lực, vật lực và nguồn lực tổ chức mà chưa quan tâm đến nguồn lực tinh thần và nguồn lực văn hóa, mặc dù như đã trình bày trong mục II có tác động hai mặt.

Văn hóa là một kho cung cấp nguồn lực sẵn sàng để các cá nhân, nhóm và tổ chức có thể tiếp nhận sử dụng. Văn hóa thường được định nghĩa như là các biểu tượng ngụ ý (tacit) và mặc định (taken-for-granted), niềm tin, giá trị, bản sắc, và chuẩn mực hành vi ứng xử của một nhóm người định hướng và tạo điều kiện cho hành động của họ trong cuộc sống hàng ngày. Thể loại nguồn lực văn hóa này cũng bao gồm các phong trào hay sự kiện có liên quan như âm nhạc, văn học, các blog, các trang web, hoặc các bộ phim/video... Edwards và Kane (2014) nhấn mạnh rằng các nguồn lực văn hóa, mặc dù phổ biến rộng rãi trong một xã hội nhất định nhưng vừa phân bố không đều (xã hội hoặc không gian), vừa khó có thể tiếp cận tổng hợp đối với các phong trào xã hội.

Nguồn lực tinh thần bao gồm tính hợp pháp, tính xác thực, hỗ trợ đoàn kết, cảm thông, và sự nổi tiếng [4]. Nguồn tinh thần khích lệ sự tự tin của các nhân vật của phong trào và từ đó có can đảm để hành động và chinh phục những khó khăn bằng cách trả lời và xác nhận câu hỏi "Điều gì tôi nên và phải làm". Nguồn lực tinh thần giúp cho người tham gia có niềm tin vào nền tảng đạo đức mà họ đã chọn. Hầu như bất kỳ tổ chức nào cũng có thể có nền tảng đạo đức của riêng họ, trong khi không phải tất cả chúng đều được xã hội công nhận.

Để tạo một nhận thức mới mang tính tự giác của đông đảo các tầng lớp nhân dân, để từ đó có thể giải quyết những vấn đề bức xúc trong GD theo phương thức XHH và những đề xuất về chủ trương và giải pháp thực tiễn phát triển GD có thể tranh thủ được sự ủng hộ rộng rãi của xã hội thì việc huy động các nguồn lực văn hóa và nguồn lực tinh thần có vai trò đặc biệt quan trọng.

Bằng nguồn lực văn hóa và tinh thần chúng ta có thể giúp cho những người tham gia XHHGD củng cố niềm tin vào chủ trương XHHGD của Đảng và Nhà nước, niềm tin vào các $\mathrm{EMO}$, đặc biệt là các trường NCL; xóa bỏ được mặc cảm vì lợi nhuận của hoạt động của các tổ chức này. Cũng bằng nguồn lực văn hóa và tinh thần chúng ta có thể giúp cho các gia đình Việt Nam dần thay đổi tư tưởng chuộng hư danh, hư học vốn là mặt trái của bản sắc hiếu học của người Việt Nam; khắc phục được tư tưởng chính danh chính thống hạn chế sự phát triển đa dạng của một nền giáo dục thích ứng với cơ chế thị trường.

Bằng nguồn lực văn hóa và tinh thần chúng ta có thể giúp cho các gia đình Việt thoát khỏi được thói quen ỷ lại vào Nhà nước thời bao cấp, tự giác nhận thức được việc chia sẻ nguồn lực và trách nhiệm đối với Nhà nước và các cơ sở 
giáo dục trong việc giáo dục và đào tạo con em của họ. Bản thân các cơ sở giáo dục cũng tự giác mở cửa nhà trường với đầy đủ các thông tin và cơ hội học tập cũng như năng lực và những hành trang khác mà nhà trường có thể cung cấp cho người học một cách đáng tin cậy.

Cuối cùng là khi đông đảo các tầng lớp nhân dân đã thay đổi được nhận thức thì thông qua việc huy động nguồn lực văn hóa và tinh thần XHHGD tự nó đã tạo ra sự hiện diện của một hệ tư tưởng mới trong việc phát triển giáo dục của đất nước.

\section{Huy động nguồn lực xã hội là giải pháp cốt lõi đẩy mạnh xã hội hóa giáo dục ở nước ta}

Để có thể huy động nguồn lực văn hóa và nguồn lực tinh thần có hiệu quả chúng ta cần xem xét vấn đề dưới góc độ của lý thuyết huy động nguồn lực (resource mobilization) cho các phong trào xã hội. Theo một lý thuyết xã hội học quan trọng trong nghiên cứu các phong trào xã hội xuất hiện vào những năm 1970 [2], huy động nguồn lực là quá trình lấy nguồn lực từ nhà cung cấp tài nguyên, sử dụng các cơ chế khác nhau, để thực hiện công việc của tổ chức để đạt được các mục tiêu đã xác định trước của tổ chức. Nói vắn tắt việc huy động nguồn lực bao gồm: tiếp cận và sử dụng nguồn lực. Khác với các nguồn nhân lực, nguồn lực vật chất và nguồn lực tổ chức mà lâu nay chúng ta đã chú trọng huy động, nguồn lực văn hóa và tỉnh thần có những đặc điểm khác nên cách tiếp cận và sử dụng cũng phải khác.

Câu hỏi được đặt ra là để huy động có hiệu quả các nguồn lực văn hóa và tinh thần thì giải pháp huy động là gì?

Để trả lời câu hỏi này, chúng ta thử tiếp cận nguồn lực theo sở hũu. Theo đó, nguồn lực có thể được phân thành hai loại: nguồn lực cá nhân và các nguồn lực xã hội. Nguồn lực cá nhân là các nguồn lực thuộc về một người; chúng bao gồm những đặc điểm đã được ghi nhận và đạt được của mỗi cá nhân như giới tính, chủng tộc, tuổi tác, tôn giáo, giáo dục, nghề nghiệp và thu nhập cũng như các nguồn lực gia đình của họ.
Những nguồn lực này thuộc sở hữu của cá nhân và với sự quản lí của cá nhân.

Nguồn lực xã hội là nguồn lực gắn kết trong mạng lưới xã hội của một người và các mối quan hệ xã hội. Đây là những tài nguyên thuộc sở hữu của những cá nhân khác mà tôi có thể khai thác trực tiếp hoặc gián tiếp. Tài sản hoặc vị thế xã hội, kinh tế, hoặc chính trị của một người bạn có thể được coi là tài nguyên xã hội của tôi. Tôi có thể tìm sự giúp đỡ của bạn bè trong việc sử dụng tài nguyên đó cho tôi để đạt được một mục đích cụ thể. Người ta đã lập luận rằng các nguồn lực xã hội được tiếp cận và sử dụng trong nhiều hoạt động của một cá nhân để đạt được các mục tiêu cụ thể và/hoặc có ý nghĩa.

Liên quan hoặc quan tâm đến khía cạnh tinh thần, trí tuệ, hoặc văn hoá của cuộc sống người ta cũng có một cách tiếp cận khác về nguồn lực đó là nguồn lực vật chất (material) và nguồn lực phi vật chất (non-material). Nguồn lực phi vật chất được Fuchs [3] định nghĩa là tính hợp pháp, lòng trung thành, mối quan hệ xã hội, các mạng lưới, các mối quan hệ cá nhân, sự quan tâm của công chúng, uy quyền, cam kết đạo đức và sự đoàn kết (Non-material: legitimacy, loyalty, social relationships, networks, personal connections, public attention, authority, moral commitment, solidarity [3]). Cũng có người định nghĩa đơn giản hơn nguồn lực phi vật chất là các nguồn lực mà bạn không thể đụng chạm (touch) được như là hạnh phúc, hòa bình, cảm giác an toàn ... Theo các định nghĩa này thì mối quan hệ xã hội (tạo nên nguồn lực xã hội) chỉ là một trong các dạng nguồn lực phi vật chất.

Mặt khác, xét về các khía cạnh của XHHGD thì những nguồn lực xã hội mới là thứ nguồn lực cần huy động để đẩy mạnh XHHGD do bản chất xã hội của nó vốn được gắn kết trong mạng lưới xã hội của một người và các mối quan hệ xã hội. Ở chừng mực nào đấy theo định nghĩa đã nêu thì nguồn lực xã hội được tiếp cận và sử dụng để huy động các nguồn lực vật chất và phi vật chất khác. Như thế có thể nói nguồn lực xã hội là một loại nguồn lực sơ cấp (primitive) để huy động các nguồn lực thứ cấp 
mà người, nhóm người hoặc tổ chức khác có cho mục tiêu của bạn hoặc tổ chức của bạn, cụ thể là cho việc đẩy mạnh XHHGD.

Ngoài ra, trong so sánh với các dạng nguồn lực của một xã hội có thể huy động được bao gồm: nhân lực, vật lực, tổ chức, văn hóa và tinh thần thì việc tiếp cận và sử dụng các nguồn lực văn hóa và đặc biệt là nguồn lực tinh thần với tư cách cá nhân và một cách trực tiếp dường như là không thể.

Nếu không có các mạng lưới xã hội và các mối quan hệ xã hội khác thì mỗi cá nhân không thể tiếp cận được các biểu tượng ngụ ý (tacit) và mặc định (taken-for-granted), niềm tin, giá trị, bản sắc, và chuẩn mực hành vi ứng xử định hướng và tạo điều kiện cho hành động của họ trong cuộc sống hàng ngày. Các cá nhân cũng không thể tiếp cận những hoạt động tập thể như nhạc hội, bình phẩm văn học, các blog, các trang web, hoặc các bộ phim/video...

Nếu không có các mạng lưới xã hội và các mối quan hệ xã hội khác thì mỗi cá nhân cũng không thể tiếp cận được sự hỗ trợ đoàn kết, hỗ trợ cảm thông, và những nhân vật nổi tiếng cũng như sự động viên, khích lệ tự tin mà từ đó có can đảm để hành động và chinh phục những khó khăn và có niềm tin vào nền tảng đạo đức mà họ đã chọn

Nói tóm lại, huy động nguồn lực xã hội là giải pháp cốt lõi cần làm để đẩy mạnh XHHGD ở nước ta, trước hết là để từ đó có thể huy động tất cả các nguồn lực có thể trong xã hội thông qua các mạng lưới xã hội và các quan hệ xã hội khác mà nguồn lực xã hội cung cấp, đặc biệt là huy động các nguồn lực văn hóa và tinh thần mà hiện nay chưa được quan tâm huy động đúng mức.

\section{Kết luận}

Trên cơ sở phân tích công tác XHHGD của nước ta dựa trên các văn bản chính thức của Đảng và Nhà nước Việt Nam và thực tiễn XHHGD trong những năm qua, bài báo đã trình bày những nguyên nhân chính của sự suy giảm hiệu quả của chính sách XHHGD. Bằng cách so sánh giữa XHHGD của nước ta với các đặc điểm cơ bản của một phong trào xã hội nói chung, chúng tôi đã rút ra nhận xét rằng các nguồn lực văn hóa và tinh thần đã chưa được coi trọng đúng mức trong XHHGD của nước ta. Bằng nguồn lực văn hóa và tinh thần chúng ta có thể giúp cho những người tham gia XHHGD củng cố niềm tin vào chủ trương XHHGD của Đảng và Nhà nước, giúp cho các gia đình Việt dần thay đổi nhận thức về việc học của con em, thoát khỏi được thói quen ỷ lại vào Nhà nước thời bao cấp, nhận thức được việc chia sẻ nguồn lực và trách nhiệm cùng với Nhà nước phát triển giáo dục; bản thân các cơ sở giáo dục cũng cần mở cửa nhà trường với đầy đủ các thông tin và cơ hội học tập cũng như năng lực và những hành trang khác mà nhà trường có thể cung cấp cho người học một cách đáng tin cậy. Khi đông đảo các tầng lớp nhân dân đã thay đổi được nhận thức thì thông qua việc huy động nguồn lực văn hóa và tinh thần XHHGD tự nó đã tạo ra sự hiện diện của một hệ tư tưởng mới trong việc phát triển giáo dục của đất nước.

Xem xét dưới góc độ của lí thuyết huy động nguồn lực cho các phong trào xã hội cũng như khía cạnh sở hữu của nguồn lực, chúng tôi đã xác định nguồn lực xã hội như là một thứ nguồn lực sơ cấp cần khai thác để huy động các nguồn lực khác. Đồng thời huy động nguồn lực xã hội cũng là giải pháp cốt lõi để huy động các nguồn lực văn hóa và nguồn lực tinh thần mà hiện nay chưa được quan tâm đúng mức trong XHHGD của nước ta.

Công trình này được tài trọ bởi đề tài cấp Nhà nuớc "Giải pháp phát triển bền vũng các truờng ngoài công lập" thuộc Chuoong trình quốc gia về khoa học giáo dục. Các tác giả xin chân thành cám ơn.

\section{Tài liệu tham khảo}

[1] J.S. Coleman, Social capital in the creation of human capital, American Journal of Sociology (Supplement) 94 (1988) S95-S120.

[2] B. Edwards, J.D. McCarthy., Resource mobilization and social movements, in D.A. Snow, S.A. Soule and H. Kriesi (eds), The 
Blackwell Companion to Social Movements, Blackwell Oxford (2004).

[3] C. Fuchs, The Self-Organization of Social Movements Systemic Practice and Action Research, 19 (1) (2006) 101-137

[4] D.M. Cress, D.A. Snow, Mobilization at the margins: resources, benefactors, and the viability of homeless social movement organizations, American Sociological Review 61(6) (1996) 1089-109.

[5] Nguyễn Văn Thắng, Một số vấn đề quản trị trong huy động nguồn lực xã hội cho giáo dục và y tế. Tạp chí Kinh tế và Phát triển 218 (2015) 11-19.
[6] Ban Chấp hành Trung Ương, Hội Khuyến học Việt Nam Báo cáo của Ban Chấp hành trung ương lần thứ 7, nhiệm kì IV (2011 - 2015) Hà Nội, 2016.

[7] Đặng Úng Vận, Nguyễn Thị Huyền Trang, Thách thức và giải pháp đối với các trường đại học ngoài công lập Tạp chí Khoa học Giáo dục 89 (2013) 16-20.

[8] M.S.A. Rao, Social Movements and Social Transformation: A Study of Two Backward Classes Movements in India Manohar (1987)

[9] P. Wilkinson Social Movement: Key Concepts in Political Science Paperback (1971).

\title{
Mobilizing Social Resources to Promote the Societalization of Education in Vietnam
}

\author{
Nguyen Thi Huyen Trang ${ }^{1}$, Tran Thi Hoai ${ }^{2}$ \\ ${ }^{1}$ Hoa Binh University, Hanoi, Bui Xuan Phai, Tu Liem, Hanoi, Vietnam \\ ${ }^{2}$ VNU Institute for Education Quality Assurance, 144 Xuan Thuy, Cau Giay, Hanoi, Vietnam
}

\begin{abstract}
Based on the Vietnamese Government's documents and the practice of societalization of education (SE) in Vietnam over the past years, the paper presents the main causes of the ineffectiveness of SE's policy and compares Vietnam's SE with the basic characteristics of a general social movement. The paper concludes that there was a need of mobilizing social resources to promote the SE in the current context.
\end{abstract}

Keywords: Societalization of education, mobilization of social resources, social movement, primary resource. 